\title{
A língua cabo-verdiana na construção da cabo-verdianidade no discurso de nativistas
}

\author{
Cloris Porto Torquato \\ Universidade Estadual de Ponta Grossa (UEPG)
}

\begin{abstract}
RESUMO: COM O OBJETIVO DE IDENTIFICAR OS VALORES E OS PAPÉIS ATRIBUÍDOS À LÍNGUA NOS DISCURSOS QUE FORMULARAM AS BASES DA IDENTIDADE CABOVERDIANA, NESTE TRABALHO SERÃO ABORDADOS TEXTOS JORNALÍSTICOS E ENSAÍSTICOS PRODUZIDOS PELO CHAMADO GRUPO NATIVISTA, PROMOTOR DA LÍNGUA CABO-VERDIANA COMO O SÍMBOLO DO ENCONTRO CULTURAL LUSO-AFRICANO, PORTANTO, DA MESTIÇAGEM. NO ENTANTO, O GRUPO ANUNCIAVA, A UM SÓ TEMPO, A LÍNGUA COMO 1) POSITIVAMENTE, O SÍMBOLO DA MESTIÇAGEM, DA CABO-VERDIANIDADE; E 2) NEGATIVAMENTE, A LÍNGUA PORTUGUESA MAL FALADA, DE MENOR VALOR SOCIAL .
\end{abstract}

ABSTRATC: THIS WORK AIMS TO IDENTIFY THE VALUES AND ROLES ASCRIBED TO CAPEVERDIAN LANGUAGE IN DISCOURSES THAT COMPOSE THE FOUNDATIONS OF CAPEVERDIAN IDENTITY, BASED ON NEWSPAPER ARTICLES AND ESSAYS PRODUCED BY THE SO-CALLED NATIVIST GROUP. THE NATIVISTS PROMOTED THE CAPEVERDIAN LANGUAGE AS SYMBOL OF THE LUSO-AFRICAN CULTURAL ENCOUNTER, NAMELY, THE MESTIZAGE; NEVERTHELESS, THEY ENUNCIATED THIS LANGUAGE AS, AT THE SAME TIME, 1) THE SYMBOL OF MESTIZAGE, THE SYMBOL OF CABO-VERDIANIDADE (POSITIVELY); AND 2) THE PORTUGUESE LANGUAGE SPOKEN BADLY, THEREFORE OF LOWER SOCIAL VALUE (NEGATIVELY).

PALAVRAS-CHAVE: LÍNGUA CABO-VERDIANA, NATIVISTAS, CABO-VERDIANIDADE, VALORES E PAPÉIS SOCIAIS.

KEYWORDS: CAPEVERDIAN LANGUAGE, NATIVISTS, CAPEVERDIAN IDENTITY, SOCIAL VALUES AND ROLES. 
este trabalho, percorremos uma das etapas da elaboração discursiva da caboverdianidade construída por grupos letrados de Cabo Verde que formaram a elite intelectual do país no período colonial, focalizando os discursos produzidos pelo grupo dos nativistas a respeito da cultura e das línguas em Cabo Verde. À luz da crítica literária e da análise sociológica, dialogamos com textos jornalísticos e ensaísticos produzidos por esse grupo. Nosso objetivo, ao focalizar a construção discursiva da cabo-verdianidade, é analisar os valores e os papéis atribuídos à língua cabo-verdiana no início da formulação identitária de Cabo Verde, identificando, assim, políticas linguísticas in vivo empreendidas por diferentes atores sociais na sociedade cabo-verdiana ${ }^{1}$.

As políticas linguísticas referem-se a ações sobre as línguas que perpassam o cotidiano das comunidades, tanto quando produzidas por atuações dos falantes (políticas in vivo) quanto nas ações engendradas sobre as línguas pelo Estado (políticas in vitro) (CALVET, 2007; e HAMEL, 1988). Fundamentamos nossa análise no conceito de política linguística in vivo, considerando que os grupos sociais, com suas particularidades históricas, sociais, políticas e econômicas, podem gerar políticas linguísticas peculiares, inseridas em políticas identitárias (de afirmação) mais amplas. O debate relativo à língua configura-se como uma ação política destes grupos, como declara BLOMMAERT (1999):

O processo político desenvolve-se através de uma série de trocas envolvendo uma variedade de atores sociais: os próprios políticos e os agentes das políticas, especialistas acadêmicos e não acadêmicos, membros do público interessados, a mídia. Debates são, político-ideologicamente, o ponto de entrada da sociedade civil na produção política: eles são (vistos como) o momento histórico durante o qual comunidades politicamente organizadas são envolvidas na construção das políticas. (BLOMMAERT, 1999, p. 8)

1 A respeito das políticas linguísticas em Cabo Verde, sugerimos a leitura de "Políticas linguísticas desenvolvidas em Cabo Verde (África)", que abarca as políticas in vivo e in vitro dos períodos colonial e pós-Independência. 


\section{A cabo-verdianidade em construção}

As diferentes elaborações do tema da identidade cabo-verdiana produzidas por distintos grupos letrados consistiram em movimentos de aproximação ou afastamento de Portugal e, consequentemente, afastamento ou aproximação de África (FERNANDES, 2002). Nesses movimentos, os intelectuais locais buscaram construir um espaço e um modo de ser próprio do cabo-verdiano no contexto colonial.

Assinalamos que os grupos letrados cabo-verdianos estavam ligados principalmente à produção literária e jornalística. Disponível aos cabo-verdianos desde meados do séc. XIX (a tipografia fora introduzida em Cabo Verde em 1842), a imprensa (jornal e revista) caracterizou-se como espaço principal da manifestação dos intelectuais locais. Cabo Verde conta com uma produção literária que, segundo FERREIRA (1987), data do século XIX, com poetas que publicaram textos na imprensa da então Metrópole e do Arquipélago.

Diferentes análises foram produzidas nos campos acadêmicos (dos estudos literários e dos estudos sociológicos) sobre a produção desses autores - poetas e escritores. Assinalamos que dentre as análises sociológicas predomina a crítica à produção dos intelectuais cabo-verdianos não tanto pelo conteúdo ou forma das obras, mas pela posição que os grupos letrados estabeleceram com a população cabo-verdiana. Essas análises concluem que, ao tematizar a cabo-verdianidade, os intelectuais constituíram-se como mediadores políticos entre diferentes instâncias de poder (administração colonial, governo português, organismos internacionais) e a população cabo-verdiana. (ANJOS, 2002; 2004; FERNANDES, 2002). Entendemos que essas análises sociológicas revelam-se adequada ao contexto intelectual cabo-verdiano. Ao partilhar esse princípio, no entanto, não estamos negando a contribuição dos grupos letrados cabo-verdianos para a construção dos discursos e dos elementos caracterizadores da identidade nacional cabo-verdiana.

FERREIRA (1987) divide a produção literária cabo-verdiana em antes e depois da Revista Claridade e informa-nos sobre a relação entre a literatura e a elaboração da identidade nacional cabo-verdiana:

Esta [a definição entre pátria cabo-verdiana e pátria metropolitana] é uma das dramáticas ambiguidades literárias destes poetas. Ambiguidade que irá ser re- 
solvida, esteticamente, pela rasura, pela ausência diríamos completa do Pai, da Pátria, por parte do grupo da Claridade (1936). O complexo edipiano será definitivamente ultrapassado com a geração da Certeza (1944) e a do Suplemento Cultural (1958) que colaborarão no parricídio definitivo - a morte do suposto Pai: o colono - assumindo-se Cabo Verde, simultaneamente, como Mátria e Pátria, restabelecendo-se assim o equilíbrio social e cultural. (FERREIRA, 1987, p. 33).

Autores que publicaram nas revistas Claridade, Certeza e Suplemento Cultural tematizaram a pertença pátria do povo cabo-verdiano a partir do estabelecimento de relações entre as culturas dos nativos das ilhas e dos portugueses e a partir das relações sócio-históricas e políticas entre Cabo Verde e Portugal.

Embora concordemos com FERREIRA (1987) que essas revistas estabeleceram as bases para a elaboração de discursos sobre a identidade cabo-verdiana, assinalamos que algumas ideias formuladas por autores que antecederam a Revista Claridade são igualmente importantes.

\section{Os nativistas}

Os primeiros cabo-verdianos que tematizaram a "cultura cabo-verdiana" e estabeleceram a díade nós/eles, respectivamente, cabo-verdianos/portugueses, foram os nativistas (nos primeiros 20 anos do século XX). O nativismo é caracterizado como um movimento literário e político, cujos autores fundadores produziram textos literários (especialmente poéticos) e jornalísticos com teor reivindicatório em favor do povo cabo-verdiano. Os principais espaços de produção dos nativistas foram a Revista de Cabo Verde e o Jornal $A$ Voz de Cabo Verde, fundado em 1911. A produção nativista esteve inserida no quadro das ideias e políticas republicanas que se estabeleceram em Portugal e repercutiram na política colonial no ultramar português.

(...) nas páginas de $\mathrm{A}$ Voz, intelectuais como Eugénio Tavares, Pedro Cardoso, Corsino Lopes, Luis Loff de Vasconcellos, protagonizaram, ao longo de anos, uma polémica sobre o "nativismo" (que começara no século passado e se prolongaria até aos anos 30). Nativismo que, no essencial, se baseava no amor à 
terra (por vezes referida como "pátria cabo-verdiana ”) crioula, no orgulho de ser cabo-verdiano , o que, para o pensamento político da época, não contradizia o facto de ser português também. (Pereira, 1979, p. 43) (grifos meus).

Em Cabo Verde, as primeiras inquietações políticas populares de reivindicação dos direitos à liberdade e à igualdade (em relação ao colonizador, ao metropolitano) foram influenciadas pela Revolução Liberal de 1820 e pela Independência do Brasil (1822). Associada a esses acontecimentos históricos anteriores, a instauração da República (1910) ampliou, nos habitantes dos territórios ultramarinos portugueses, a imaginação política da igualdade e da construção de uma cidadania lusitana.

Nos grupos letrados cabo-verdianos especificamente, os ideais republicanos fomentaram a esperança do fim da exploração e da desigualdade no sistema colonial e impulsionaram o anseio por participarem da política no sistema político português. Entretanto, as esperanças do grupo não se concretizaram. Desejavam participar dos trabalhos administrativos em Cabo Verde, mas eram enviados para o trabalho agrícola em São Tomé. Diante da impossibilidade de obter igualdade de direitos, os grupos letrados cabo-verdianos passaram a negociar novos espaços sociais e políticos que poderiam ocupar, consolidando, a partir daí, a afirmação da elite letrada local.

Para demarcar a especificidade cabo-verdiana em relação aos portugueses metropolitanos, o grupo dos nativistas afirmava a presença, na cultura caboverdiana, de elementos culturais africanos que marcariam a distinção entre o lusitano e o cabo-verdiano. Esse grupo formulou a cabo-verdianidade a partir da mestiçagem, entendida como o entrecruzamento de características portuguesas e africanas, indicando "uma dualidade de pertença e lealdade" (FERNANDES, 2002, p. 76).

No discurso dos nativistas, a demarcação da presença de elementos africanos na cultura cabo-verdiana provém especialmente da influência que as ideias panafricanistas exerceram sobre esse grupo. Eugénio Tavares, um dos principais autores do nativismo, foi exilado nos Estados Unidos por ter feito denúncias contra o governo de Cabo Verde. No exílio, teve contato com o pan-africanismo e inseriu em seu discurso o mote da "África para os africanos".

Em texto no qual expunha sua posição contra uma possível venda das colônias portuguesas para pagamento de dívidas do governo português, Eu- 
génio Tavares defendeu, para a busca de autonomia política das colônias, a união dos cabo-verdianos aos demais africanos que viviam sob a colonização portuguesa. No texto, intitulado "Autonomia", publicado no jornal A Alvorada, o poeta afirmou: "Portugueses-irmãos, sim; Portugueses-escravos, nunca. Havemos de ter nosso Monroe: a África para os africanos" (TAVARES, apud MONTEIRO, 1997, p. 68). (grifos meus)

A autonomia política, pretendida por Tavares, não implicava a negação da nacionalidade portuguesa; antes, procurava garantir que os territórios ultramarinos portugueses se mantivessem sob o governo português. "Sim, nós somos nativistas. Amamos mais a Portugal que a todas as nações do mundo! Amamos mais a Cabo Verde que a todas as outras terras de Portugal! Mais adoramos o nosso lar que os lares dos nossos melhores amigos" (TAVARES, apud MONTEIRO, 1997, p. 157).

Eugénio Tavares, ao lado de Pedro Cardoso e Luis Loff de Vasconcellos, denunciou a falta de ação política diante da fome vivida pelo povo cabo-verdiano e a falta de instrução básica e secundária nas ilhas e se opôs à prestação de serviço pelos cabo-verdianos nos trabalhos agrícolas em São Tomé. Esses nativistas reivindicavam o progresso de Cabo Verde e colocavam-se como mediadores entre o governo colonial e os grupos populares, procurando concomitantemente reivindicar melhorias para o arquipélago e conscientizar o povo da necessidade dessas melhorias. Um trecho do texto "Ao povo caboverdeano” (1910), de Eugénio Tavares, explicita o lugar de mediação construído pelo grupo: "A ti Lázaro, me dirijo", assim começa o texto, e continua:

Víctima da dissolução do meio em que fadejas; pessoa civil sem valor real; força política sem consciência de direito; dizer-te vivo para o dever, é calumniar a tua incapacidade cívica e intelectual. (...) O que têm feito, por ti, esses que, com proficuidade, podem exercer benéfica acção, moral e política? Quando é que, para elevar teu nível moral ou econômico, sacrificaram elles, a mínima parcella do seu tempo ou do seu dinheiro? Quando é que deixaram de baldrocar com a tua confiança? Quando, se cançaram de abusar da tua ignorância? (...) E tu? Tu dormes. Dormes, e não há meio de te acordar; (...) dormes o somno cataléptico de que só se acorda nos humbraes da morte. E dormes porque te falta a comprehenção dos teus direitos (...) (TAVARES, apud. LIMA, 2005). 
Dirigindo-se ao povo cabo-verdiano, o autor recorre à segunda pessoa do singular (tu dormes, tua, ti) para designar e aproximar-se do seu interlocutor, e utiliza a terceira pessoa do plural (eles, sacrificaram) para referir-se àqueles que detêm o poder moral e político, a administração colonial. No texto, o autor procura apresentar-se como alguém que tenta (em vão) acordar o povo do sono provocado pela falta de conhecimento dos seus direitos.

De forma retórica, Tavares dirige-se ao povo cabo-verdiano. A maior parte da população cabo-verdiana, entretanto, não poderia ler o texto por ser analfabeta. Os leitores de Tavares eram, portanto, o grupo letrado nativo ao qual pertencia o autor e os funcionários portugueses da administração colonial. Tavares se posiciona assim como mediador entre os grupos populares sem escolarização e a administração colonial, que, segundo o autor, abandonou o povo cabo-verdiano ao sono da ignorância.

Tavares inclui-se no povo cabo-verdiano, mas se exclui dos grupos populares. Esses são caracterizados pela ignorância, que provém da falta de escolarização. Como o autor é escolarizado (e domina a língua portuguesa) seria diferente dos grupos populares, das massas ignaras. No entanto, o autor partilha com esses grupos o fato de ser nativo da Província de Cabo Verde. Embora seja cabo-verdiano e, por isso, abandonado pela administração, conseguiu transpor algumas barreiras criadas pelo colonialismo. É essa diferença que o separa das massas e que permite ao grupo letrado incumbir-se da mediação entre sistema colonial e grupos populares.

O movimento nativista promoveu a mestiçagem como espaço de luta contra a exploração e opressão colonial. A reivindicação por uma identidade mestiça, distinta daquela do colonizador, apontava para a emergência das práticas e valores populares que permaneciam na sociedade cabo-verdiana apesar dos esforços dos colonizadores em coibi-las e extingui-las. Dentre essas práticas, ressaltamos as produções culturais populares em língua cabo-verdiana: morna ${ }^{2}$, finaçons e curcutiçans (estilos musicais característicos de Cabo Verde).

Os nativistas pesquisaram elementos da cultura popular e produziram textos em língua cabo-verdiana: Eugénio Tavares ${ }^{3}$ é reconhecido por sua produ-

2 A respeito da morna, ver o texto "Morna - Expressão do Lirismo Cabo-Verdiano", de Benilde Justo Caniato.

3 Foi publicado em 1932 o livro Morna - Cantigas crioulas, de Eugénio Tavares. 
ção de mornas em língua cabo-verdiana. Segundo LIMA (2005), através das mornas Eugénio Tavares deu sua "contribuição à coesão da sociedade caboverdiana”. Pedro Cardoso, importante autor nativista, é reconhecido como produtor de poesias em cabo-verdiano e por seu trabalho etnográfico de pesquisa de produções culturais populares. Sob o título Folclore cabo-verdiano, Cardoso publicou, em 1933, uma compilação de músicas e poesias colhidas nas ilhas Fogo, Santiago e Brava.

As primeiras manifestações de afirmação da língua cabo-verdiana realizadas pelos nativistas consistiram na publicação de textos poéticos escritos nessa língua, na publicação de artigos de jornal e na apresentação de conferências que defendiam o uso do cabo-verdiano com a finalidade de refutar o argumento (corrente na época) de que essa língua era a principal responsável pela dificuldade de os cabo-verdianos aprenderem o português. O grupo nativista promoveu a língua cabo-verdiana como o símbolo do encontro cultural luso-africano, da mestiçagem. Essa língua passou a configurar-se como um componente central da cabo-verdianidade que o grupo tentava construir.

\section{A língua cabo-verdiana em foco - valores e papéis sociais}

As diversas perspectivas construídas a respeito das línguas pelos grupos letrados em Cabo Verde estão inseridas no processo de produção das políticas do Estado (especialmente o colonial, com a restrição de uso das línguas locais) e dialogam com essa produção. Esses diálogos são concretizados, sobretudo, entre o grupo escolarizado (a elite) cabo-verdiano e as políticas oficiais do Estado.

Os nativistas vivenciaram a intensificação das restrições às línguas locais nas políticas linguísticas coloniais da virada do século XIX para o XX e no início desse século. Nesse contexto, opondo-se à condição de indígena, caracterizaram-se pela elaboração de uma nacionalidade na qual o indivíduo caboverdiano constituía-se como cidadão português, apto a requerer os direitos enunciados na Constituição e reivindicar os ideais republicanos liberais, com particularidades étnico-culturais em relação aos portugueses da metrópole.

Sendo cidadãos portugueses, eram-no com uma peculiaridade: eram mestiços. Compartilhavam da herança étnico-racial portuguesa, o que os dife- 
renciava dos indígenas africanos, e da herança africana, o que os diferenciava em relação a outros cidadãos portugueses. O símbolo dessa mestiçagem era a língua, reconhecida, nesse período, como um dialeto da língua portuguesa. Era a "língua portuguesa mal sabida e mal ensinada pelos mestres, e mal aprendida e mal falada pelos discípulos" (CARDOSO apud. FERNANDES, 2005, p. 148). Em um artigo intitulado "Língua de Pretos", Eugênio Tavares, no mesmo sentido de Pedro Cardoso, afirma que o "dialecto" local deveria ser concebido como a língua portuguesa mal ensinada aos escravos. (TAVARES, apud MONTEIRO, 1997, p. 218)

Resultando de um ensino deficiente aos "pretos" e de uma mestiçagem "pelo contacto de duas raças", o dialeto cabo-verdiano constituiria um registro da transformação da língua portuguesa. A transformação pela qual havia passado essa língua consistia em ter assumido "vícios prosódicos" e "tonalidades bárbaras de muitos vocábulos sonoros" decorrentes de influências exercidas "em longas gerações de colonos, por multidões de escravos". Essas influências eram vistas pelo autor como "imorredoura herança, as reminiscências bárbaras que eivaram a própria língua dos senhores" e eram tão explícitas "que, num gráfico em que tentássemos descrever a distância em que, pelas ilhas, os respectivos dialectos correm a par do português, veríamos, por exemplo, que em Santiago, onde viviam compactas multidões de escravos rodeando um pequeno número de senhores, essa distância se alarga, ao passo que, na Brava, onde era diminuta a população africana, ela se estreita" (idem.).

Partindo da ideia de que "o dialecto cabo-verdiano" era um dialeto da língua portuguesa que se havia formado pelo contato com línguas africanas, as quais haviam deixado marcas na língua portuguesa, o autor, em diálogo com outros discursos que circulavam pela sociedade cabo-verdiana, afirma: "a chamá-lo língua de pretos, melhor seria dizê-lo língua de brancos mal ensinada a pretos". Além de indicar que a língua cabo-verdiana estava sendo chamada de "língua de pretos", o autor aponta que havia quem risse da possibilidade de essa língua ser escrita (“(...) nunca me ri dos que afirmam que o dialecto cabo-verdiano deve ser grafado (...) porque me pareceu sempre que o riso com ares superiores podia ser sintoma de inferioridade") e quem negasse essa possibilidade ("Aligeirando razões, permita-se-me a seguinte conclusão: o dialecto cabo-verdiano pode falar-se e grafar-se (...)".) Diante do debate social sobre a língua cabo-verdiana, Tavares afirma a necessidade de estudo 
das transformações que geraram o dialeto e reitera que os estudiosos das línguas deveriam dedicar-se ao estudo do "dialecto crioulo": "E deve ser certo que o interesse filológico que leva ao estudo da língua em que nos chegaram as "Saudades" de Bernardim, não seja maior que o interesse glotológico que recomenda o estudo do dialecto em que as deliciosas crioulas gorjeiam os seus amores." (Ibidem.)

Ao enfatizar a viabilidade a e necessidade de estudo do "crioulo", o autor procura valorizar a língua que expressa a identidade mestiça do povo caboverdiano. Além disso, a mestiçagem linguística é expressa como a manutenção da língua portuguesa: as transformações (no tempo e por influência do meio - o longo encontro entre africanos e portugueses) na língua portuguesa que levaram ao "crioulo" "documentam a história da nossa colonização". A língua cabo-verdiana se caracterizaria, para esse grupo letrado, como o símbolo da mestiçagem, do encontro linguístico-cultural, e da colonização portuguesa. Devia-se às condições da colonização em Cabo Verde o fato de ser o "crioulo" uma língua mal falada pelos portugueses e mal ensinada aos africanos.

Para Fernandes (2005), ao afirmar que a língua portuguesa era mal falada e mal ensinada pelos portugueses, Pedro Cardoso estaria depreciando o colonizador e, desta forma, desconstruindo a "épica civilizatória portuguesa". Sob este enfoque, os poetas nativistas Pedro Cardoso e Eugênio Tavares estariam problematizando as bases do grupo dominante. Uma vez que os colonizadores (em Cabo Verde) eram caracterizados como um grupo inábil dentre os dominantes e na medida em que a língua indicava o grau de civilização, não haveria possibilidade de o dominador realizar a contento sua empreitada civilizatória no que se referia à língua portuguesa como língua civilizada. Prova disso é que o dominador ensinou mal a língua. Assim, se em Cabo Verde havia um "dialeto" do português, era por responsabilidade dos próprios portugueses. Desse modo, segundo Fernandes, Cardoso estaria desconstruindo um dos argumentos de superioridade do colonizador (a língua), de modo a aproximar-se dele.

Embora concordemos com Fernandes que o discurso de Pedro Cardoso e de Eugênio Tavares pode gerar a desconstrução da superioridade linguística do grupo português, parece-nos que o posicionamento de ambos os poetas nativistas em relação à língua cabo-verdiana revela, no seu discurso, a predominância das atitudes e valores do dominador em relação à língua do domi- 
nado: eles concordariam com a perspectiva de que o cabo-verdiano era uma língua desqualificada, era uma variedade menor da língua portuguesa. Uma consequência possível desse juízo emitido sobre a língua cabo-verdiana é que a cultura veiculada nessa língua pode também ter menor valor que a cultura "civilizada". Ao distinguir grupos no interior de uma unidade nacional, a atribuição de valores de inferioridade a uma língua e uma cultura pode provocar a discriminação/inferiorização do grupo ao qual a língua e a cultura desprestigiadas estão relacionadas.

Embora a atribuição à língua cabo-verdiana de uma certa desqualificação não possa ser negada no discurso dos poetas, havia por parte deles o desejo de valorizar o "crioulo", prova disso é que Eugênio Tavares fala da necessidade de estudo desse "dialecto".

$\mathrm{Na}$ constituição de uma política linguística in vivo que se forja como debate em torno da questão linguística, esse grupo mantém o prestígio e o lugar de dominação política e étnico-cultural da língua portuguesa e a desqualificação e o lugar de subjugado da língua cabo-verdiana, embora se registrem os esforços do grupo na valorização dessa língua. $\mathrm{O}$ argumento que legitimaria a língua e a cultura cabo-verdianas como critérios de pertença, na realidade, as deslegitima diante da língua e da cultura do colonizador.

Pode corroborar essa análise o fato de posteriormente os próprios portugueses ter usado esses argumentos para explicar o surgimento do cabo-verdiano, como fez Rodrigo de Sá Nogueira (1984), ao indicar que o crioulo seria uma metamorfose, uma simplificação, do português na boca dos negros, que não tiveram disciplina escolar para o estudo da língua portuguesa. A ausência dessa disciplina seria oriunda da falta de interesse das "pessoas incultas" e dos brancos "de pouca cultura e sem preocupações culturais" que povoaram as ilhas. Para Nogueira, somava-se a essa ausência a incapacidade de o negro se adaptar à estrutura (complexa) da língua portuguesa.

Os colonizadores escolarizados e cultos do século XX, diferentes daqueles que povoaram o arquipélago nos séculos XV e XVI, afirmavam que "o dialeto crioulo" resultara do encontro linguístico entre brancos incultos e negros incapazes. O encontro linguístico-cultural que havia deixado heranças dos grupos em contato, que poderia particularizar e alçar o cabo-verdiano a uma situação de dialeto da língua portuguesa, portanto, símbolo da proximidade e da equiparação entre cabo-verdianos e metropolitanos, é justamente o que o 
desqualifica e o rebaixa, impossibilitando que se construa, a partir da língua, um movimento nacionalista autêntico cabo-verdiano.

A escolarização, que implicava a aprendizagem da língua portuguesa, formou um pequeno grupo letrado, com vistas a suprir a necessidade de mediadores entre a administração colonial e os habitantes da ilha. A formação desse grupo mediador gerou a disputa pelos cargos públicos em que concorriam os portugueses da Metrópole e a elite letrada local. Delimitando espaços de ação, os grupos letrados locais procuraram elaborar a especificidade cabo-verdiana em relação ao metropolitano e aos demais africanos.

Guiados pela tensão entre a particularidade cabo-verdiana e a pertença nacional portuguesa, os nativistas mantiveram-se como membros da nação portuguesa, ora recorrendo à condição legal jurídico-administrativa, que lhes afirmava a cidadania lusitana, ora recorrendo ao capital que assegurava essa cidadania, o capital linguístico-cultural (a língua portuguesa), reforçando a política linguística do Estado português e marginalizando os que não possuíam tal capital. Neste contexto, forja-se o debate sobre a língua cabo-verdiana, a qual é a um só tempo o símbolo da mestiçagem, da cabo-verdianidade - por isso, valorizada - e a língua portuguesa mal falada - portanto, de menor valor social que a língua dominante.

\section{Referência Bibliográfica}

ANJOS, José C. Gomes dos. Intelectuais, literatura e poder em Cabo Verde: Lutas de Definição da Identidade Nacional. Porto Alegre (Brasil): UFRGS/IFCH: Praia (Cabo Verde): INIPC, 2002.

"A condição de mediador político-cultural em Cabo

Verde: intelectuais e diferentes versões da identidade nacional”. In: Etnográfica - Revista do Centro de Estudo de Antropologia Social, Lisboa, Vol. VIII (2), 2004, pp. 273-295.

BLOMMAERT, Jan. “The debate is open”. In: BLOMMAERT, Jan. (Ed.) Language Ideological Debates. Berlin - New York: Mounton de Gruyter, 1999.

CALVET, Louis-Jean. As políticas linguisticas. (Trad. de Isabel de Oliveira Duarte, Jonas Tenfen e Marcos Bagno). São Paulo: Parábola Editorial: IPOL, 2007.

CANIATO, Benilde Justo. "Morna - Expressão do Lirismo Cabo-Verdiano". In: CANIATO, Benilde Justo. Percursos pela África e por Macau. Cotia: SP: Ateliê Editorial, 2005 
FERNANDES, Gabriel. A diluição da Africa: uma interpretação da saga identitária caboverdiana no panorama político (pós)colonial. Florianópilos: Ed. Da UFSC, 2002.

- Cabo Verde: Formações discursivas (trans)nacionalistas de uma sociedade crioula politicamente sitiada. Florianópolis: UFSC, 2005. (Tese de Doutorado)

FERREIRA, Manuel. Literaturas africanas de expressão portuguesa. São Paulo: Ática, 1987.

HAMEL, Rainer Enrique. «La política del lenguage y el conflicto interétnico: problemas de investigación sociolinguística". In: ORLANDI, Eni P. Política Linguística na América Latina. Campinas, SP: Pontes, 1988. pp. 41-73.

LIMA, Antonio Germano. "Eugénio Tavares: contribuição para a investigação histórico-cultural da sociedade cabo-verdiana." (Texto apresentado em uma comunicação no Instituto superior de Educação, de Cabo Verde, em 27 de outubro de 2005.) Disponível em: http://transcv.blogspot.com/2006/12/eugnio-tavarescontribuio-para.html

NOGUEIRA, Rodrigo de Sá. "Prólogo". In: SILVA, Baltazar Lopes. O dialecto crioulo de Cabo Verde. Lisboa: Imprensa Nacional/ Casa da Moeda, 1984.

PEREIRA, Carlos Lopes. A Voz de Cabo Verde. In: África : Literatura. Arte. Cultural dir. Manuel Ferreira. - Lisboa : África Editora, Lda. - n. 14 (1979), pp. 27-44.

TAVARES, Eugénio. "Língua de pretos". In: MONTEIRO, Félix (recolha, org. e prefácio). Eugénio Tavares - pelos jornais. Praia, Instituto Cabo-verdiano do Livro e do Disco, 1997 [Texto original publicado em O Manduco, n. 11, jan. de 1924].

TORQUATO, Cloris Porto. Políticas linguísticas desenvolvidas em Cabo Verde (África). Campinas, SP : [s.n.], 2009. (Tese de Doutorado) 